\title{
Endoscopic management of obstruction due to an acquired bronchial web
}

\author{
Kevin L Kovitz MD FCCP FACP ${ }^{1}$, Mahtab B Foroozesh MD ${ }^{1}$, \\ Jose $M$ Goyos DO ${ }^{1}$, Edmundo R Rubio MD ${ }^{2}$
}

\begin{abstract}
KL Kovitz, MB Foroozesh, JM Goyos, ER Rubio. Endoscopic management of obstruction due to an acquired bronchial web. Can Respir J 2002;9(3):189-192.

Bronchial webs are thin, membrane-like diaphragms that may obstruct the airway. Several congenital cases have been reported. Though rare, the true incidence of these lesions is probably underestimated because many of them are unrecognized. The case of a 71-year-old woman with an acquired bronchial web causing right main stem bronchus obstruction that went unrecognized for 47 years post-trauma is reported. The lesion was successfully treated using rigid bronchoscopy with laser therapy, balloon dilation and stent placement. This is the first reported case of an acquired bronchial web formation. It is also the first reported case that was successfully treated with this technique.
\end{abstract}

Key Words: Bronchial web; Bronchoscopy; Laser; Membrane; Stent
Traitement endoscopique d'une obstruction due à la formation acquise d'un « réseau " bronchique

RÉSUMÉ : Les « réseaux » bronchiques sont des diaphragmes minces, semblables à des membranes, qui peuvent obstruer les voies respiratoires. La documentation fait état de plusieurs cas d'origine congénitale. Bien qu'ils soient rares, leur véritable incidence est probablement sous-estimée du fait que beaucoup d'entre eux passent inaperçus. Voici un cas de formation acquise d'un « réseau » bronchique qui a causé l'obstruction de la bronche souche droite chez une femme de 71 ans et qui a été diagnostiqué 47 ans après un traumatisme. La lésion a été traitée au moyen d'un bronchoscope rigide muni d'un rayon laser, par dilatation par ballonnet et par la pose d'une endoprothèse. Il s'agit du premier cas signalé de formation acquise d'un « réseau » bronchique ainsi que du premier cas signalé de traitement fructueux réalisé de la sorte.
$\mathrm{B}$ ronchial webs are membrane-like structures that cause airway occlusion. To date, all reported cases have been congenital. These lesions are often unrecognized due to their nonspecific respiratory symptoms. The case of a patient with such a lesion, but of an acquired nature due to thoracic trauma, is presented. A novel approach to treatment with rigid bronchoscopy was used, with excellent results.

\section{CASE PRESENTATION}

A 71-year-old woman with a history of severe asthma was referred to Tulane University Health Science Center's Interventional Pulmonology Service (New Orleans, Louisiana) for evaluation. Her medical history included mechanical ventilation and bilateral tube thoracostomy due to right rib fractures and bilateral pneumothoraces after

${ }^{1}$ Section of Pulmonary Disease, Critical Care and Environmental Medicine, ${ }^{2}$ Department of Medicine, Tulane University, New Orleans, Louisiana Correspondence: Dr Kevin L Kovitz, 1430 Tulane Avenue, SL-9, New Orleans, Louisiana 70112, USA. Telephone 504-588-2250,

fax 504-587-2144, e-mail kkovitz@tulane.edu 


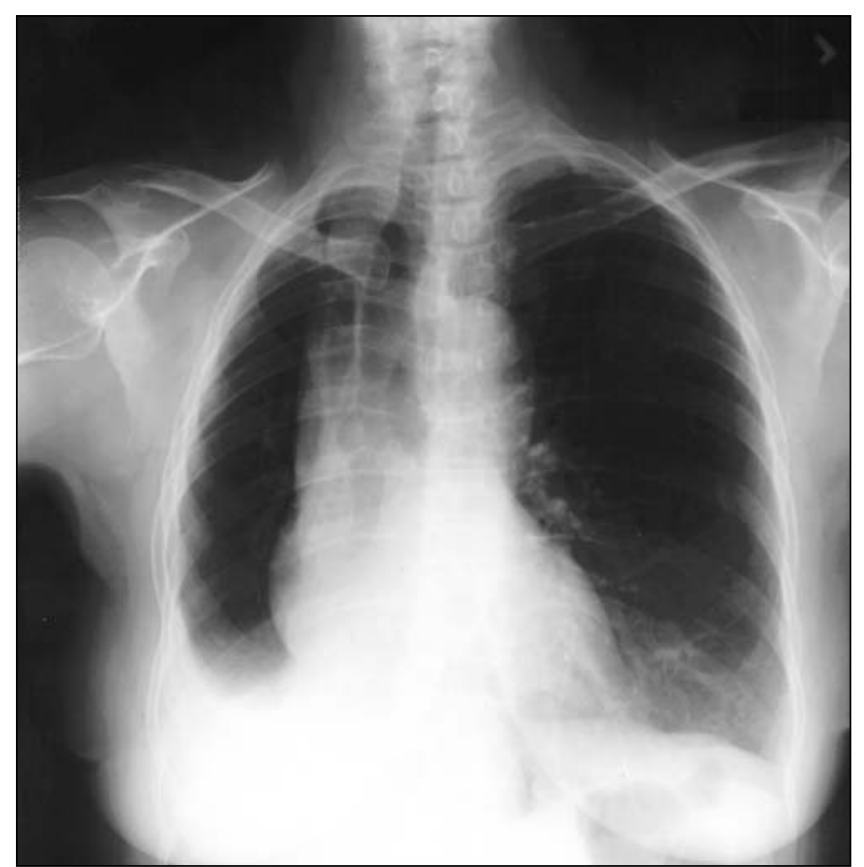

Figure 1) Posterolateral view of the chest demonstrating partial collapse of the right lung with ipsilateral mediastinal shift

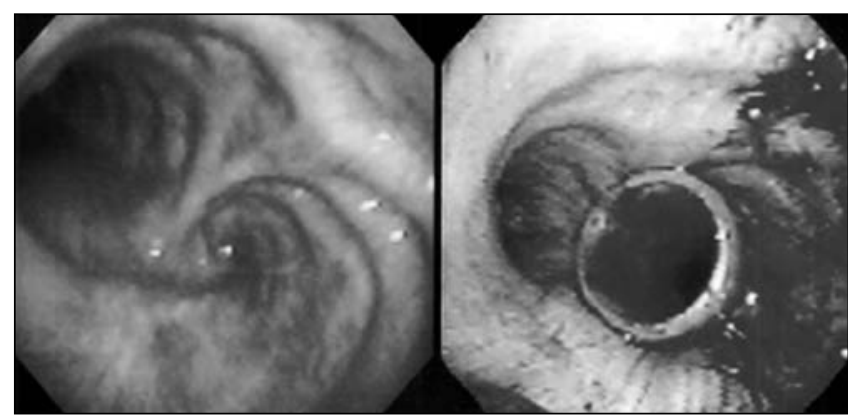

Figure 2) Left Endoscopic view of the main carina showing a membranous structure completely occluding the right main bronchus. Right Endoscopic view of the main carina after laser therapy and stenting now showing a patent right main bronchus

a motor vehicle accident in 1953. Due to a prolonged need for ventilatory support, she underwent tracheostomy, which was removed six months later. To the best of the authors' knowledge, evaluation of the airway with bronchoscopy was not performed at that time. In addition, she suffered from pneumonia in 1978 and 1995. The patient had no history of smoking.

Eight months before presentation, the patient began experiencing increasing dyspnea and cough. Pulmonary function testing then showed a moderate obstructive defect with hyperinflation and normal diffusing capacity. A flexible bronchoscopy performed three months later at another institution revealed a right bronchial web immediately distal to the carina, with a pinhole lumen. This was differentiated from a stenosis by the presence of an obstructing membrane in the airway. A chest roentgenogram performed at the time was unremarkable, and a chest

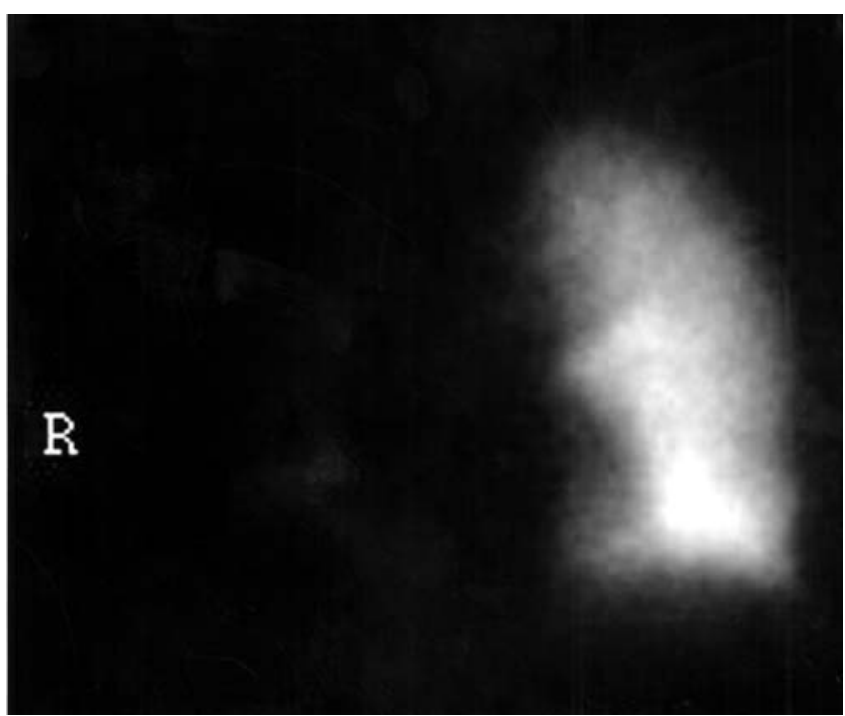

Figure 3) The patient's lung perfusion scan before rigid bronchoscopy shows minimal perfusion of the right $(R)$ lung

computed tomography scan showed the webbed segment without masses or adenopathy. She underwent flexible bronchoscopy and laser therapy at the same institution, with partial opening of the right mainstem bronchus one month later. Two days later, due to decreased responsiveness and tachypnea, she was intubated. A chest roentgenogram showed right lung atelectasis. A follow-up bronchoscopy disclosed only partial opening of the right mainstem bronchus. She gradually improved and was successfully extubated four days later. One week later, she underwent a repeat flexible bronchoscopy with laser ablation of the remaining bronchial web, resulting in near complete resolution of the obstruction. She was discharged after two days. One week later, a surveillance bronchoscopy showed a partially occluded $(8 \mathrm{~mm})$ right mainstem bronchus with mild inflammation and scarring. Shortly after discharge and over the next two months, the patient noticed recurrent and progressive dyspnea and cough. Her physical examination showed decreased breath sounds on the right side. Results of a routine chemistry panel and hemogram were normal. A chest roentgenogram showed partial collapse of the right lung with ipsilateral mediastinal shift (Figure 1). Repeat flexible bronchoscopy revealed a bronchial web fully obstructing the right mainstem bronchus (Figure 2). She was then referred to the authors' institution. A ventilation and perfusion scan showed no ventilation to the right lung, with $92 \%$ flow to the left lung and $8 \%$ to the right (Figure 3). The patient was taken to the operating room, and after flexible bronchoscopy that confirmed the presence of the bronchial web with complete occlusion of the right mainstem bronchus, she was intubated with a $12 \mathrm{~mm}$ external diameter Dumon-Harrell rigid bronchoscope (Bryan Corporation, USA). A 22-gauge Wang needle (Bard Endoscopy Technologies, USA) was used to create a hole in the obstructing web, confirming the presence of a distal airway by suctioning air. A rigid suction catheter was 


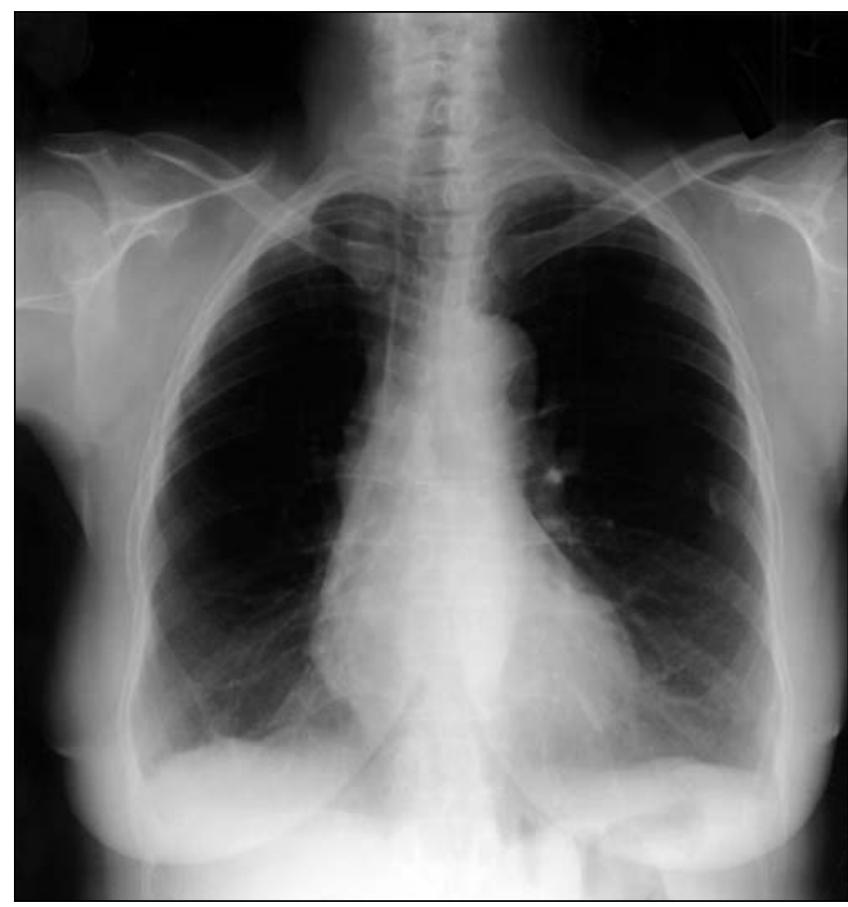

Figure 4) A follow-up posterolateral view of the chest after interventional bronchoscopy shows resolution of the previous lung collapse with return of the mediastinal structures to the midline

then advanced through the created opening to enlarge it. Serial balloon dilations of this area were performed with a variable diameter balloon (Boston Scientific Microvasive, USA), starting with a 6 to $8 \mathrm{~mm}$ diameter balloon and up to a $15 \mathrm{~mm}$ diameter balloon, and inflating for $1 \mathrm{~min}$ at each diameter (1). Inspection of the right subsegmental bronchi revealed only minor trauma to the secondary carina between the basilar and superior segment of the lower lobe. A neodynium:yttrium aluminum garnet laser (MBB Medilas 4060 Fiberton; Dornier Medical Systems Inc, USA) with repeated $30 \mathrm{~W}, 0.7 \mathrm{~s}$ intermittent firings was used to cut stress points in the webbed area. Subsequently, a $12 \times 30 \mathrm{~mm}$ Dumon type silicone stent (Bryan Corporation, USA) was placed in the right mainstem bronchus (Figure 2). The patient was discharged the next day. On follow-up one month later, she reported resolution of symptoms. Her chest roentgenogram showed re-expansion of the right lung (Figure 4). Repeat ventilation and perfusion scans showed equal ventilation of both lungs, with $32 \%$ perfusion to the right lung and $68 \%$ to the left (Figure 5). Six months later, a repeat bronchoscopy showed adequate patency of the right main bronchus, and the stent was removed. Flexible bronchoscopy the following month showed a patent right main stem with minimal granulation tissue (Figure 6). The patient remains asymptomatic.

\section{DISCUSSION}

Bronchial webs are extremely rare. A MEDLINE search from 1966 to July 2000 revealed that all reported cases were congenital in nature. Most of these cases went initially

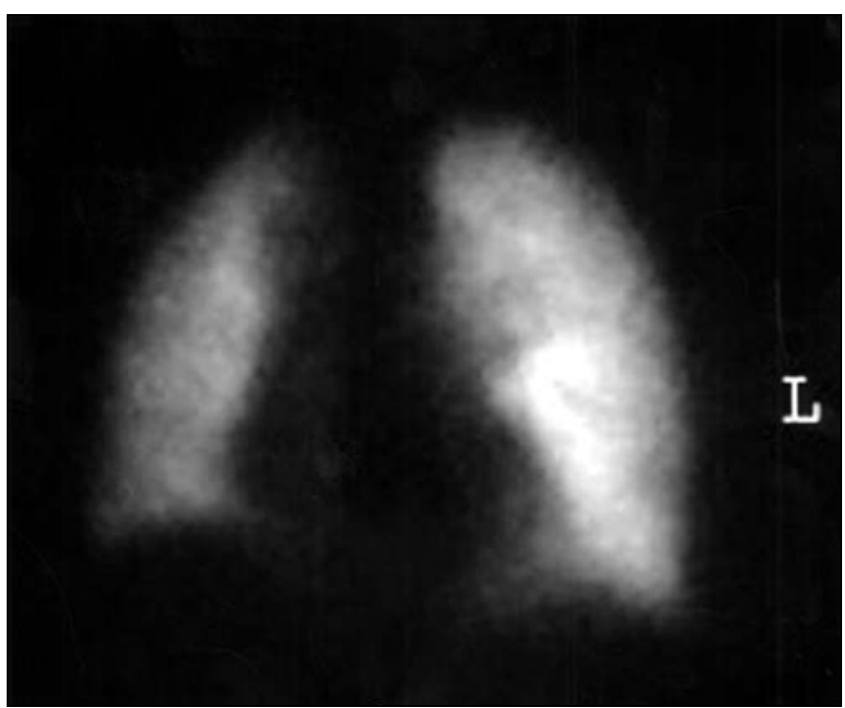

Figure 5) A two-month follow-up lung perfusion scan after successful opening of the right bronchus showing reperfusion of the right lung with $32 \%$ flow to the right. L Left

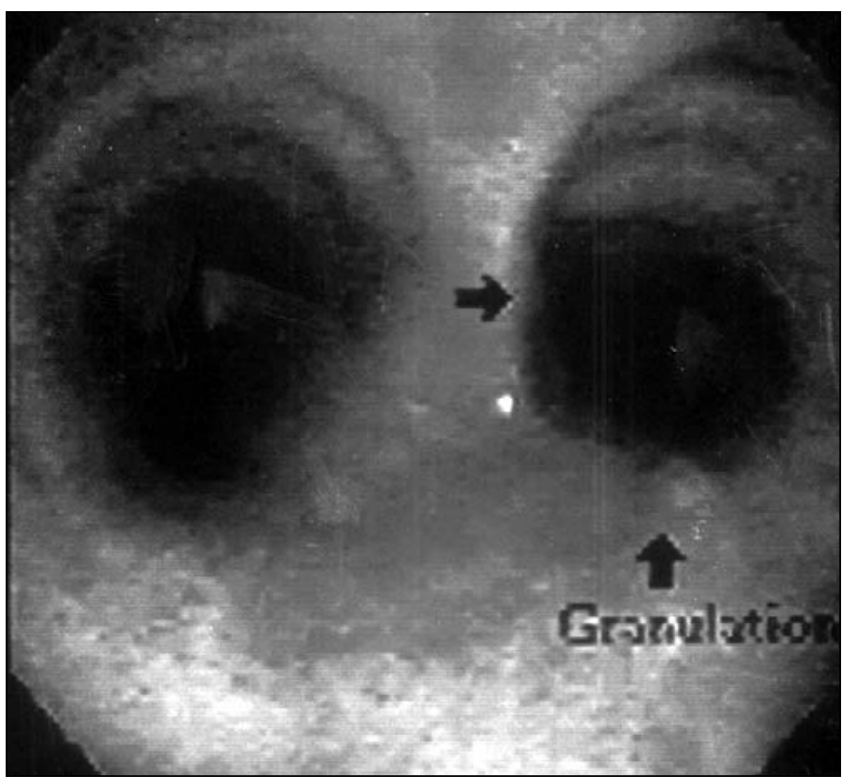

Figure 6) Endoscopic view of the main carina one month after removal of the stent showing good airway patency of the right main bronchus with minimal granulation tissue

unrecognized due to the nonspecific nature of symptoms. The diagnosis was made using bronchoscopy and bronchography. With one exception, all of the cases had been diagnosed during childhood. Patronas et al (2), however, described a case diagnosed by bronchography in a 47-yearold man. Their patient was noted to have a history of multiple pneumonia and hemoptysis since childhood.

Our research of the literature indicates that the present patient is the first reported case of an acquired bronchial web. We believe that the lack of symptoms as a child and early youth argue against a congenital nature for this bronchial web. Furthermore, the severe thoracic trauma 
that she suffered may explain the development of an airway lesion that was misdiagnosed as asthma over the years. The worsening of her symptoms, probably associated with the progression of her other medical problems, eventually prompted closer scrutiny and discovery. The acquired nature of this lesion is also reinforced by the reversible changes of her pulmonary perfusion, which would not be expected if this had been a congenital malformation.

Tracheobronchial tears following trauma are frequently overlooked and can be life-threatening. The tears are usually within $2 \mathrm{~cm}$ of the carina. Bronchial lesions most often involve the right mainstem bronchus (3). They require early surgical repair, especially when causing a significant air leak. Minor cases that involve mainly the mucosa and less than one-third of the circumference of the airway can be managed more conservatively with follow-up bronchoscopy (4). Our case demonstrates the need for bronchoscopic evaluation of patients presenting with asthma-type symptoms, especially asymmetric and focal wheezing, even years after chest trauma occurs, to rule out an airway stricture.

\section{REFERENCES}

1. Kovitz KL, Conforti JF. Balloon bronchoplasty: when and how. Pulm Perspect 1999;16:1-3.

2. Patronas NJ, MacMahon H, Variakojis D. Bronchial web diagnosed by bronchography. Radiology 1976;121:526.

3. Kiser AC, O’Brien SM, Detterbeck FC. Blunt tracheobronchial injuries: treatment and outcomes. Ann Thorac Surg 2001;71:2059-65.

4. Shaker KG, Holingsworth HM, Irwin RS, et al. Tracheobronchial injuries caused by blunt trauma. J Intensive Care Med 1995; 10:226-33.

5. McElvein RB. Laser endoscopy. Ann Thorac Surg 1981;32:463-7.
McElvein (5) demonstrated the benefits and safety of laser treatment in 1981. He treated 18 patients, two of whom were reported to have 'webs' as the cause of their airway obstruction. The details of these two cases, however, were not discussed in the paper. Endoscopic treatment with the combination of laser, balloon dilation and stent placement has not been previously reported for use in these lesions. In any case, these techniques have been extensively evaluated and found to be a safe and effective way to treat both benign and malignant airway obstruction, and have a positive impact in patient's symptoms and functional status (6-9). For lesions not amenable to bronchoscopic management, surgical sleeve resection may be an option.

The increased perfusion to the right lung after the resumption of ventilation indicates that there was minimal distortion or damage to the underlying vascular bed. This is also supported by the symptomatic improvement noted by the patient after the procedure. Bronchoscopy with laser and stenting is once again shown to be of benefit in the treatment of patients with large airway stenosis.

6. Colt HG, Dumon JF. Airway stents: present and future. Clin Chest Med 1995;16:465-78.

7. Stephens KE Jr, Wood DE. Bronchoscopic management of central airway obstruction. J Thorac Cardiovasc Surg 2000;119:289-96.

8. Cavaliere S, Venuta F, Foccoli P, et al. Endoscopic treatment of malig-nant airway obstructions in 2,008 patients. Chest 1996;110:1536-42.

9. Vergnon JM, Costes F, Bayon MC, et al. Efficacy of tracheal and bronchial stent placement on respiratory functional tests. Chest 1995;107:741-6. 


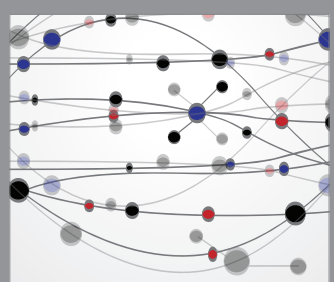

The Scientific World Journal
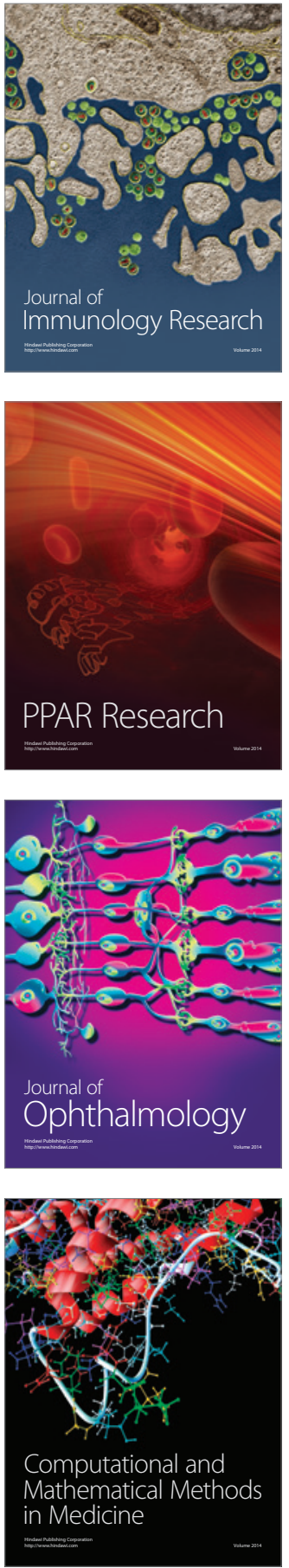

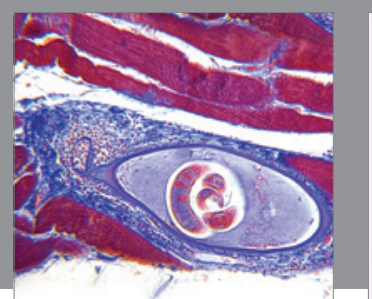

Gastroenterology Research and Practice

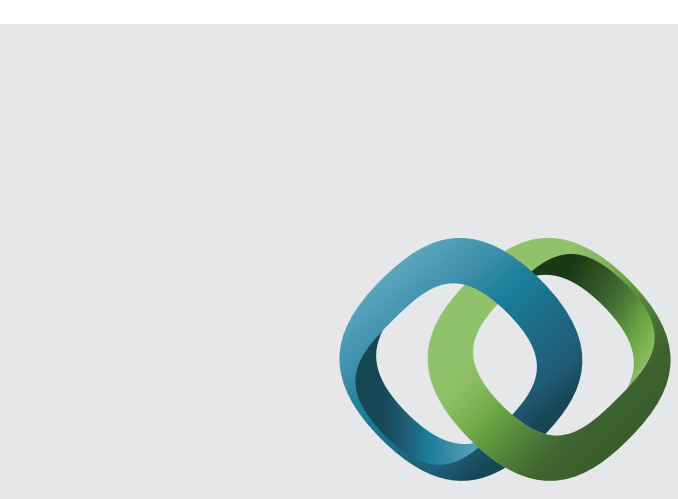

\section{Hindawi}

Submit your manuscripts at

http://www.hindawi.com
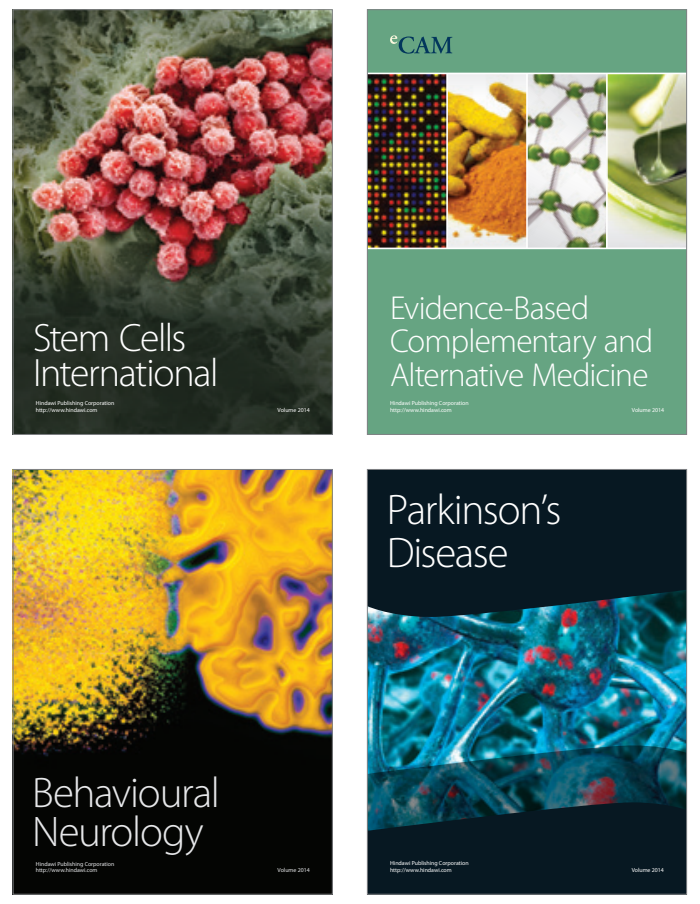
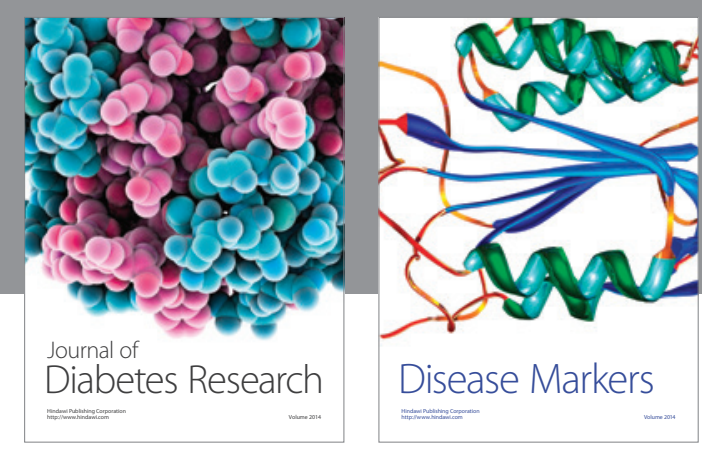

Disease Markers
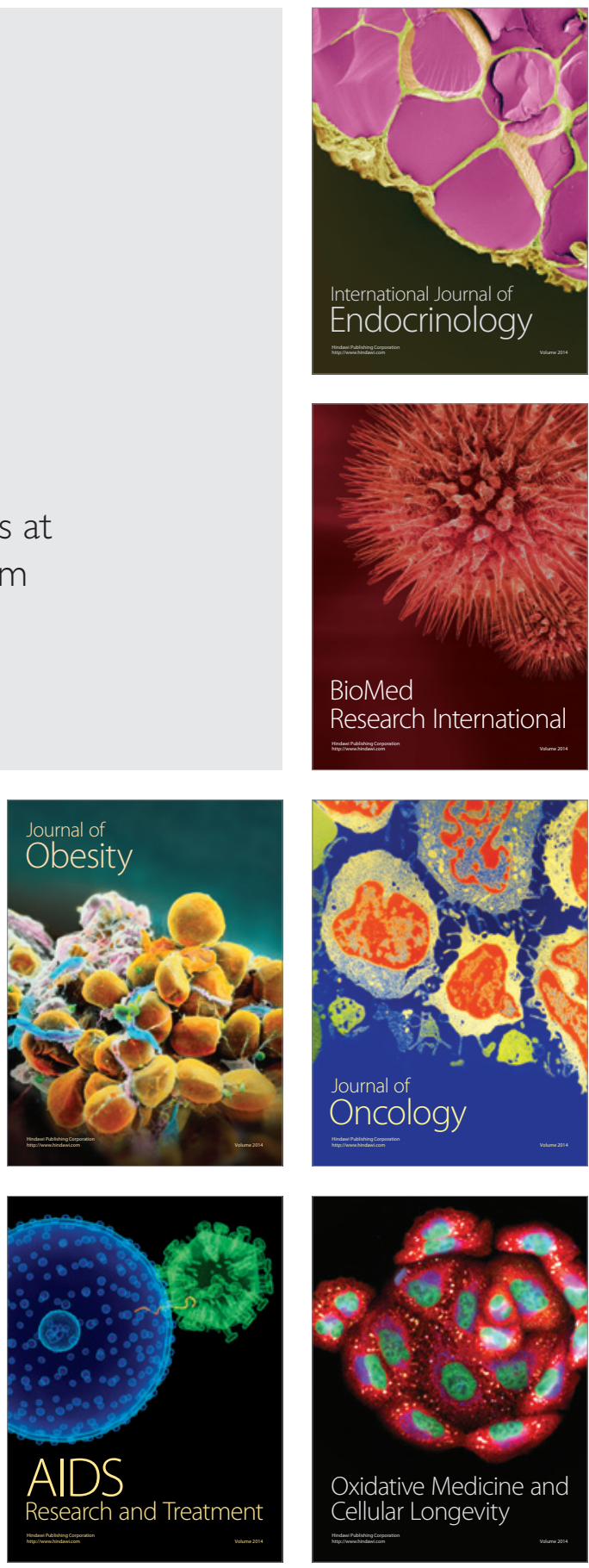